\title{
Predator discrimination and anti-predator behaviour by wintering parids: an experimental study
}

\author{
Olav Hogstad
}

Norwegian University of Science and Technology, NTNU University Museum, NO-7491 Trondheim, Norway; e-mail: Olav.Hogstad@ntnu.no

\begin{abstract}
Even though birds' perceptions of risk are biased towards starvation avoidance in winter, recognition of the level of threat of a predator is an important precondition. To investigate the ability of three tit species (Blue Cyanistes caeruleus, Great Parus major and Willow Tits Poecile montanus) to recognise dangerous and harmless objects, I studied their mobbing reaction and the latency of the tits to return to the feeder after being exposed to life like models of Eurasian Sparrowhawk Accipiter nisus, Siberian Jay Perisoreus infaustus and Three-toed Woodpecker Picoides tridactylus, birds similar in size (about $30 \mathrm{~cm}$ ) but differing widely from each other in feeding. The mobbing level was higher and the latency time of each of the tit species were significantly longer after presenting the Sparrowhawk than the Siberian Jay, whereas the woodpecker aroused no specific reaction. The tits apparently recognised the individual predator species and made decisions on their perceptions of the threat level.
\end{abstract}

Key words: Predator recognition; parids; mobbing

\section{INTRODUCTION}

Predation risks have negative effects due directly to mortality or indirectly by elevating physiological stress through changes in behaviour. As food intake is often connected with the risk of predation, there is a tradeoff between the need to search for food and to avoid predators (e.g. Bonter et al. 2013).

In winter, environmental conditions cause an increased energy expenditure in small birds, due to reduced day length, food abundance and food availability. Birds therefore need to spend nearly all daylight time foraging to meet energy requirements for winter survival (Jansson et al. 1981). Thus, in winter time during periods of cold weather, the birds' perceptions of risk are biased towards starvation avoidance (Bonter et al. 2013). However, recognition of the level of threat of a potential predator is an important precondition. Underestimating a danger posed by a predator can be fatal, on the other hand evaluating a harmless animal as threatening can also be detrimental (Caro 2005) because high individual vigilance reduces the available time for feeding and so increases starvation risk. Discrimination of potential predators is therefore a necessary precondition for assessing the levels of threat.

To describe the variety of anti-predator behaviour for small passerines, different stuffed predator models have been used in experimental studies (Desrochers et al. 2002, MacLeod et al. 2005). Several studies on predator recognition have been made during the breeding season to observe the alarm and mobbing reaction of the adult birds or the broods to a predator, and the ability to recognise dangerous and harmless objects was proved in most studies (e.g. Knight \& Temple 1986, Rytkönen \& Seppola 1995, Caro 2005).

Studies made outside the breeding season are few, and anti-predatory behaviour has mainly been focused on mobbing intensity (e.g. Desrochers 1989, Griesser 2009, Tvardikova \& Fuchs 2012). Because previous studies mainly used predator dummies of different sizes, it may be unclear whether the birds tested were able to recognize the different predator species (Palleroni et al. 2005, Griesser 2009).

In the present study, I examine whether the parids Great Tit Parus major, Eurasian Blue Tit Cyanistes caeruleus and Willow Tit Poecilemontanus discriminate between different avian predators and harmless species in winter with respect to the trade-off between food gain and the risk of predation. I used lifelike models of birds occurring abundantly in the area: male Eurasian Sparrowhawk Accipiter nisus, Siberian Jay Perisoreus infaustus and Three-toed Woodpecker Picoides tridactylus, bird species similar in size (about $30 \mathrm{~cm}$ ) but differing widely from each other as predators on tits. The Sparrowhawk is probably the most dangerous predator for small passerines (Rytkönen et al. 1988, Slagsvold \& Dale 1996, Solonen 1997), the Siberian Jay is less dangerous but not harmless (Hogstad, unpublished data), while the woodpecker hardly represents any danger to tits (Hogstad 1988a).

I studied the mobbing reaction of the tits to the stuffed objects and their latency time to return to the feeder after being exposed to the dummies. Mobbing 
is an anti-predator behaviour used by prey to harass a predator by attacking it. At the same time, the predator often is unable to attack the individual because several individuals are cooperatively attacking it (Curio 1978, Welbergen \& Davies 2009). Although mobbing may have several overlapping functions (e.g. Welbergen \& Davies 2009), one of the main functions is to signal to the predator that it might be more expedient to hunt elsewhere and to vacate its present foraging area (Flasskamp 1994). If intensity of mobbing is related to the threat of a potential predator (e.g. Templeton et al. 2005), it may be predicted that the tits would mob the Sparrowhawk with greater intensity than the Siberian Jay.

Although the tit species differ somewhat in size (Great Tit $15 \mathrm{~cm}$, Blue Tit $12 \mathrm{~cm}$, Willow Tit $12 \mathrm{~cm}$ ), they are all extremely vulnerable to the Sparrowhawk. If all the tit species recognise the hawk as a deadly threat, it may be suggested that their risk perception towards this predator would be similar for each species and all would evaluate the predation risk of the hawk significantly higher than that of the jay. Since the Blue and Willow Tits are smaller than the Great Tit, it may also be suggested that these species will evaluate the threat level of the Siberian Jay higher than Great Tits would. Furthermore, as the Three-toed Woodpecker hardly represents any danger to the tits, none of the species should show any anti-predatory behaviour towards the woodpecker dummy.

\section{METHODS}

The study was carried out in a subalpine mixed forest, mainly composed of Scots Pine Pinus sylvestris and Downy Birch Betula odorata in Budal, in central Norway. At this latitude, winter most often sets in around mid October. Potential predators of small passerines in the area include small mustelids such as Stoat Mustela erminea and Weasel M. nivalis, small owls such as Tengmalm's Owl Aegolius funereus and Hawk Owl Surnia ulula in twilight or at night, and Sparrowhawk, Siberian Jay, Magpie Pica pica and Great Grey Shrike Lanius excubitor during the day. The tits studied were often found in mixed-species flocks of five to eight individuals, which tended to move through the forest together.

Five series of experiments (October 2011, January and March 2012, and January and March 2013), were made at each of five stationary feeders with sunflower seeds. Thus, there were 105, 55, and 74 days, respectively, between each series of experiments within each of the winter seasons.

The feeders were situated 400-500 m apart, and each of them was placed within a winter territory of a Willow Tit pair. Although the feeders could be empty of sunflower seeds for several days, they were regularly visited by resident Willow Tits. Each experiment started when Willow and Great Tits were present.

In total 25 trials were made involving Willow and Great Tits and 11 to 14 involving Blue Tits (11 to the hawk, 14 to the jay, 13 to the woodpecker).

The risk of the birds being habituated to the stuffed bird was minimised by showing the dummies only once per second month. The predators and the woodpecker presentations were done in random order on consecutive days at each of the feeders. After presenting one of the models, the trial was repeated with another model on the same feeder in one of the following three days.

Each of the feeders was mostly visited by 3-5 Willow Tits, of which an adult male and adult female were colour ringed at three of the feeders. Because winter flocks of Willow Tits generally consist of a resident territorial pair of adults and 2-4 juveniles (Hogstad 1987), I consider the unmarked birds of these three flocks as juveniles. Two of the feeders were frequently visited by $2-3$ Great Tits, of which an adult male and an adult female were colour ringed, and two mated pairs of Blue Tits (not ringed). Occasionally the feeders were also visited by finches. In cases where finches arrived before the tits, I removed the sunflower seeds from the feeder and started the experiment later in the day.

Because of the relatively long distance between the feeders, I never observed that any of the colour ringed tits visited more than one of the specific feeders, and therefore consider the data to be of individuals of different flocks. Furthermore, as there was a long time between each series of trials, and no variations were found in mobbing levels or latency times of the species between the different series (see Results), the birds were apparently not habituated to the dummies and I therefore consider the data to be independent of each other.

Presentation of the dummies involved quickly approaching the feeder and placing the dummy on a $1.5 \mathrm{~m}$ wooden pole around $1-2 \mathrm{~m}$ from the feeder. The dummy was mounted at the same height as the feeder and positioned facing it. I retreated immediately, hiding about 10-15 m away from the feeder. Based on earlier experiences, my presence apparently had no impact on the birds.

Each dummy was presented for 5 minutes, and the tits' behaviour was noted: mobbing during dummy presentations, and latency time after removal of the dummy.

The highest mobbing response of each species was noted during the first 2 minutes after presentation of the dummies. Mobbing response was scaled as follows: (1) no response; (2) weak response with approaching and retreating to/from the dummy, some moving restless around it or hovering 3-5 $\mathrm{m}$ from it while giving alarm calls; (3) strong response with intense movements and display close to the dummy $0.5-2 \mathrm{~m}$ including dive 
Table 1. Mobbing level (1-3: none to strong response) of Blue,- Great- and Willow Tits exposed to a life-like dummy of Eurasian Sparrowhawk, Siberian Jay and a Three-toed Woodpecker mounted about $1.5 \mathrm{~m}$ from a feeder.

\begin{tabular}{lcccc}
\hline \multirow{2}{*}{ Mobbing level } & \multicolumn{3}{c}{ Number of trials } \\
\cline { 3 - 5 } & & Blue Tit & Great Tit & Willow Tit \\
\hline Eurasian Sparrowhawk & 1 & 0 & 0 & 1 \\
& 2 & 4 & 7 & 16 \\
Siberian Jay & 3 & 7 & 18 & 8 \\
& 1 & 3 & 4 & 6 \\
Three-toed Woodpecker & 2 & 3 & 14 & 6 \\
& 3 & & & \\
& 2 & 2 & 11 & 23 \\
& 3 & 0 & 0 & 2 \\
\hline
\end{tabular}

attacks at the predator.

The latency time (minutes) to return to the feeder after removing the dummy was noted for the first individual of each species. If the predator had still been around, those returning first would have been at greater risk of being killed. In the cases I could identify the bird through colour rings, I registered sex and age (adults or juveniles).

All tests are two-tailed, and were performed using SPSS 23. Significance was accepted at $\mathrm{p} \leq 0.05$.

\section{RESULTS}

\section{Mobbing behaviour}

As expected, the tits clearly distinguished the predators Sparrowhawk and Siberian Jay from the Three-toed Woodpecker. Thus, the tits responded in roughly the same way to the dummies: after alarm calling and diving for cover, they gradually started to mob the Sparrowhawk and the Siberian Jay, whereas no specific reaction was observed towards the woodpecker (Table $1)$.

The mean mobbing levels of the tits towards the hawk (Blue: 2.6, Great: 2.7, Willow: 2.3) were about
1.3 times higher than towards the jay (Blue: 2.0, Great: 2.1, Willow: 1.7).

The mobbing level of each of the tit species was significantly higher for the Sparrowhawk than for the Siberian Jay (Blue Tit: median $=3.0$ vs 2.0; MannWhitney Test $\mathrm{z}=2.32, \mathrm{n}_{1}=11, \mathrm{n}_{2}=14, \mathrm{p}=0.02$; Great Tit: median $=5.0$ vs $3.5 ; \mathrm{z}=3.29, \mathrm{n}_{1}=\mathrm{n}_{2}=25, \mathrm{p}=$ 0.001 ; Willow Tit: median $=2.0$ vs $1.0 ; \mathrm{z}=2.62, \mathrm{n}_{1}=$ $\mathrm{n}_{2}=25, \mathrm{p}=0.009$ ).

No differences were found in mobbing levels between Blue and Great Tits when encountering the hawk $\left(\mathrm{z}=0.50, \mathrm{n}_{1}=11, \mathrm{n}_{2}=25, \mathrm{~ns},\right)$, or between Blue and Willow Tits $(\mathrm{z}=1.80, \mathrm{p}=0.07)$, whereas the mobbing level of Great Tits was higher than that of Willow Tits (median 3.0 vs 2.0, $\mathrm{z}=2.86, \mathrm{p}=0.004$ ).

No significant differences were found in mobbing levels between the tit species after encountering the jay ( $\mathrm{z}=0.29-0.69$, ns).

\section{Latency time}

Each of the tit species apparently evaluated the Sparrowhawk as more dangerous than the Siberian Jay, and their latency time (minutes) before returning to the feeder was significantly higher after presenting

Table 2. Mean latency time (minutes) of Blue, Great and Willow Tits in returning to the feeder after being exposed to a life-like dummy of Sparrowhawk, Siberian Jay and a Three-toed Woodpecker mounted about $1.5 \mathrm{~m}$ from the feeder. SD and number of trials are given in parentheses.

\begin{tabular}{lccr}
\hline Dummy model species & Blue Tit & Great Tit & Willow Tit \\
\hline Eurasian Sparrowhawk & $5.0(1.12 ; 11)$ & $5.4(1.05 ; 25)$ & $5.0(1.51 ; 25)$ \\
Siberian Jay & $2.1(0.92 ; 14)$ & $3.7(1.74 ; 25)$ & $3.0(1.95 ; 25)$ \\
Three-toed Woodpecker & $1.5(0.96 ; 13)$ & $1.5(0.65 ; 25)$ & $1.3(0.65 ; 25)$ \\
\hline
\end{tabular}


the hawk than after presenting the jay (Blue Tit: mean $=5.0$ vs $2.1 ; \mathrm{t}_{23}=7.20, \mathrm{p}<0.001$; Great Tit: mean $=5.4$ vs $3.7 ; \mathrm{t}_{48}=4.09, \mathrm{p}<0.001$; Willow Tit: mean $=5.0$ vs $3.0 ; \mathrm{t}_{48}=4.02, \mathrm{p}<0.001$; Table 2 ).

No significant differences were found in latency times between the tit species after encountering the hawk ( $\mathrm{p}>0.05$, ns), whereas after presenting the Siberian Jay, Great Tits returned later than Blue Tits $\left(\right.$ mean $=3.7$ vs $\left.2.1, \mathrm{t}_{37}=3.3, \mathrm{p}<0.01\right)$. No differences were found between Great and Willow Tits $(p>0.05)$.

Surprisingly, the largest of the tits, the Great Tit, returned later than the smaller Blue Tits after presenting the Siberian Jay. The Blue Tits apparently were willing to accept a higher predator risk than the Great Tits.

Each of the species had a similar reaction toward the three dummies during the five different series and did not vary in mobbing levels or latency times (One Way ANOVA, $\mathrm{p}>0.05$ ). The only exception was the Great Tits which varied in mobbing level towards the hawk dummy $\left(\mathrm{F}_{4,24}=2.88, \mathrm{p}=0.05\right)$.

The Blue Tits waited about 2.4 times longer before returning to the feeder after encountering the hawk than the jay (5.0 vs 2.1 minutes), while the Great (5.4 vs 3.7) and Willow Tits (5.0 vs 3.0 minutes) waited about 1.5 times longer.

\section{Latency time related to social rank}

Adult males, being socially dominant over adult females, took bigger risks and returned to the feeder somewhat sooner than females after encountering the Sparrowhawk, Great Tits significantly so (Table 2; mean $=5.08, \mathrm{n}=6$ vs $6.19, \mathrm{n}=8, \mathrm{t}_{12}=2.85, \mathrm{p}<0.05$ ). Although the difference between sex of Willow Tits was not statistically significant (mean $=5.25, \mathrm{n}=2$ vs $6.17, \mathrm{n}=3, \mathrm{t}_{3}=1.53, \mathrm{p}=0.22$ ), the juvenile Willow Tits returned significantly earlier than the adults (mean = $3.83, \mathrm{n}=12$ vs $\left.5.80, \mathrm{n}=5, \mathrm{t}_{15}=3.24, \mathrm{p}<0.01\right)$. Thus, the lowest-ranked juvenile Willow Tits were the first to return to the feeder after encountering the hawk, while the dominant birds returned later.

After the presentation of the Siberian Jay, no significant difference was found between adults and juvenile Willow Tits $($ mean $=4.67, \mathrm{n}=3$ vs 3.11, $\mathrm{n}=9$, $\left.\mathrm{t}_{10}=1.38, \mathrm{p}=0.20\right)$. Any age difference for the Great and Blue Tits were not estimated due to small sample sizes.

Relationship between levels of mobbing and latency time

No correlations were found between mobbing and latency time after presenting the Sparrowhawk $\left(r_{s}=\right.$ 0.0-0.36). After presenting the Siberian Jay, however, positive correlations were found between mobbing and latency time for all species (Blue Tit: $\mathrm{r}_{\mathrm{s}}=0.48, \mathrm{n}=14$, $\mathrm{p}=0.08$; Great Tit: $\mathrm{r}_{\mathrm{s}}=0.65, \mathrm{n}=25, \mathrm{p}<0.001$; Willow Tit: $\left.\mathrm{r}_{\mathrm{s}}=0.59, \mathrm{n}=25, \mathrm{p}<0.01\right)$.

\section{DISCUSSION}

The tits of all three species obviously evaluated the Sparrowhawk as more dangerous than the Siberian Jay since there was about a twofold increase in return time after being presented with the hawk compared to the jay. The Siberian Jay is, however, far from harmless, and I have seen jays killing Redpolls Carduelis flammea foraging birch seeds in the snow. On the other hand, I have also observed Siberian Jays and tits foraging only 15-20 $\mathrm{m}$ from each other without any signs of aggressive behaviour from the tits. The tits may therefore comprehend a jay as a facultative predator (e.g. Ehrlich \& McLaughlin 1988).

The results presented here support the suggestion that tits make decisions on the basis of threat level: the Sparrowhawk as a very dangerous predator, and the Siberian Jay as less dangerous, but far from harmless. Thus, the results also confirm the suggestion that the tits are able to distinguish between predators of the same size. Rytkönen \& Seppola (1995) found that responses towards the Pygmy Owl Glaucidium passerinum were generally more intense than those towards the Sparrowhawk. Similarly, Curio et al. (1983) found that Great Tit not only differentiated between different orders of birds of prey, but also among different genera of owls.

Templeton et al. (2005) showed that alarm calls of Black-capped Chickadees Parus atricapillus varied with the size of predator. However, Berankova et al. (2015), testing Great Tits with dummies of Sparrowhawks in natural and reduced sizes under laboratory conditions, found that the Sparrowhawks, regardless of size, evoked fear in the tits.

Engaging in mobbing behaviour carries real risks and predators do sometimes catch mobbers (Hogstad unpubl.). Potential prey individuals should therefore adapt the intensity of their behaviour to minimize such risks (Pavey \& Smyth 1998).

If the intensity of mobbing is related to the threat of a potential predator, as suggested by Templeton et al. (2005), the findings from the present study strengthen his statement. In addition, the positive relationships found between mobbing level and latency time on returning after the presentation of the Siberian Jay dummy, show the importance of waiting before returning to the feeder after a mobbing of a predator.

Obviously, if the predator had still been around, those returning first would have been at greater risk of depredation. The tits therefore spend more time on vigilance before they start to feed again after an attack. If latency time reflects the tits' perceptions of the threat 
level, Blue Tits showed more "bravery" than Great Tits towards the Siberian Jay. As also found by Tvardikova \& Fuchs (2012), Blue Tits apparently were willing to accept higher predator risks than other tit species.

The alpha males of the tits took greater risks and returned to the feeder sooner than the females after encountering the Sparrowhawk. The findings that alpha males returned before the adult females are in accordance with earlier observations (Curio et al. 1983, Griesser \& Ekman 2005) and may be explained as mate protection (e.g. Hogstad 1995). As Willow Tits, and to a lesser extent, Great and Blue Tits associate in pairs and maintain long-term pair bonds for years, there may be a benefit in protecting their mate.

As found in the present study and in other field experiments with tits encountering a Sparrowhawk dummy in winter, subordinates resume their foraging activity significantly sooner than dominants (Tufted Titmouse Parus bicolor, Blue, Great and Willow Tits (Waite \& Grubb 1987, De Laet 1985, Hegner 1985, Hogstad 1988a), because of different hunger levels. If high rank conveys any advantage in finding or obtaining food, then dominants could afford to wait longer than hungrier, low-ranked birds, before returning to a feeder. The individual birds therefore have to adjust their time as a response to their perceived risk of starvation and predation. In accordance with this, Jansson et al. (1981) showed that when extra food was provided, the number of Willow Tits killed by small owls decreased. Further, low-ranked flock members improved their winter survival significantly (Hogstad 1988b).

Birds apparently assess the predation risk during food searching and evaluate the fear level, and adapt their behaviour accordingly.

Acknowledgments. I am grateful to Hans Christian Pedersen for valuable comments on the manuscript.

\section{REFERENCES}

Berankova, J., Vesely, P. \& Fuchs, R. 2015. The role of body size in predator recognition by untrained birds. Behavioural Processes 120: 128-134.

Bonter, D.N., Zuckerberg, B., Sedwick, C.W. \& Hochachka, W.M. 2013. Daily foraging patterns in free-living birds: exploring the predation-starvation trade-off. Proceedings of the Royal Society B, Biological Sciences 280: 20123087. doi:10.1098/rspb.2012.3087

Caro, T.M. 2005. Antipredator defenses in birds and mammals. University of Chicago Press, London.

Curio, E. 1978. The adative significance of avian mobbing. I. Teleonomic hypotheses and predictions. Zeitschrift der Tierpsychologie 48: 175-183.

Curio, E., Klump, G. \& Regelmann, K. 1983. An anti-predator response in the Great Tit (Parus major) - is it tuned to predator risk? Oecologia 60: 83-88.

De Laet, J.F. 1985. Dominance and anti-predator behaviour of Great Tits Parus major: a field study. Ibis 127: 372 377.

Desrochers, A. 1989. Sex, dominance and microhabitat use in wintering Black-capped Chickadees: a field experiment. Ecology 70: 636-645.

Desrochers, A., Belisle, M. \& Bourque, J. 2002. Do mobbing calls affect the perception of predation risk by forest birds? Animal Behaviour 64: 709-714.

Ehrlich, P.R. \& McLaughlin, J.F. 1988. Scrub Jay predation on Starling and swallows - attack and interspecific defense. Condor 90: 503-505.

Flasskamp, A. 1994. The adaptive significance of avian mobbing. 5. An experimental test of the move on hypothesis. Ethology 96: 322-333.

Griesser, M. 2009. Mobbing calls signal predator category in a kin group-living bird species. Proceedings of the Royal Society B, Biological Sciences. 276: 2887-2892.

Griesser, M. \& Ekman, J. 2005. Nepotistic mobbing behaviour in the Siberian Jay, Perisoreus infaustus. Animal Behaviour 69: 345-352.

Hegner, R.E. 1985. Dominance and anti-predator behaviour in Blue Tits (Parus caeruleus). Animal Behaviour 33: 762-768.

Hogstad, O. 1987. Social rank in winter flocks of Willow Tits Parus montanus. Ibis 129: 1-9.

Hogstad, O. 1988a. Social rank and antipredator behaviour of Willow Tits Parus montanus in winter flocks. Ibis 130: 45-56.

Hogstad, O 1988b. The influence of energy stress on social organization and behaviour of Willow Tits Parus montanus. Fauna norv. Ser. C, Cinclus 11: 89-94.

Hogstad, O. 1995. Alarm calling by Willow Tits, Parus montanus, as mate investment. Animal Behaviour 49: 221-225.

Jansson, C., Ekman, J. \& von Brömssen, A. 1981. Winter mortality and food supply in tits (Parus spp.). Oikos 37: 313-322.

Knight, R.L. \& Temple, S.A. 1986. Nest defense in the American Goldfinch. Animal Behavior 34: 887-897.

MacLeod, R., Gosler, A.G. \& Cresswell, W. 2005. Diurnal mass gain strategies and perceived predation risk in the Great Tit Parus major. Journal of Animal Ecology 74: 956-964.

Palleroni, A., Hauser, M. \& Marler, P. 2005. Do responses of galliform birds vary adaptively with predator size? Animal Cognition 8: 200-210.

Pavey, C.R. \& Smyth, A.K. 1998. Effects of avian mobbing on roost use and diet of Powerful Owls, Ninox strenua. Animal Behavior 55: 313-318.

Rytkönen, S. \& Seppola, M. 1995. Vicinity of Sparrowhawk nest affects Willow Tit nest defense. Condor 97: 10741078

Rytkönen, S., Kuokkanen, P. \& Hukkanen, M. 1988. Prey selection by Sparrowhawks Accipiter nisus and characteristics of vulnerable prey. Ornis Fennica 75: 77-87.

Slagsvold, T. \& Dale, S. 1996. Disappearance of female 
Pied Flycatchers in relation to breeding stage and experimentally induced molt. Ecology 77: 461-471.

Solonen, T. 1997. Effect of Sparrowhawk Accipiter nisus predation on forest birds in southern Finland. Ornis Fennica 74: 1-14.

Templeton, C.S., Greene, E. \& Davis, K. 2005. Allometry of alarm calls: Black-capped Chickadees encode information about predator size. Science 308: 19341937.

Tvardikova, K. \& Fuchs, R. 2012. Tits recognize the potential dangers of predators and harmless birds in feeder experiments. Journal of Ethology 30: 157-165.

Waite, T.A. \& Grubb, T.C. 1987. Dominance, foraging and predation risk in the Tufted Titmouse. Condor 89: 936940.

Welbergen, J.A. \& Davies, N.B. 2009. Strategic variation in mobbing as a front line of defense against brood parasitism. Current Biology 19: 235-240.

Received 11 August 2017. Accepted 15 September 2017 